\title{
FIBER-REINFORCED CONCRETE FOR RIGID ROAD PAVEMENTS MODIFIED WITH POLYCARBOXYLATE ADMIXTURE AND METAKAOLIN
}

Scientific paper

(Received: 12 March 2021; accepted: 6 October 2021)

\author{
Andrey Mishutin \\ Odessa State Academy of Civil Engineering and Architecture, Odessa, Ukraine, Professor \\ Sergii Kroviakov \\ Odessa State Academy of Civil Engineering and Architecture, Odessa, Ukraine, Assistant Professor \\ Vitalii Kryzhanovskyi \\ Odessa State Academy of Civil Engineering and Architecture, Odessa, Ukraine, Engineer \\ Corresponding author: vitolloscience@gmail.com \\ Lucia Chintea \\ Odessa State Academy of Civil Engineering and Architecture, Odessa, Ukraine, PhD student
}

\begin{abstract}
Increasing the strength and durability of road surfaces is crucial. Therefore, the concrete compressive strength, flexural strength, frost, and abrasion resistance of fiber-reinforced concrete for rigid pavements are investigated in this study an experiment is performed based on an optimal plan, in which four factors of concrete composition are varied: the amounts of Portland cement, polypropylene fiber, metakaolin, and polycarboxylate type admixture. Experimental statistical models for investigating the effects of composition factors on concrete properties are established. It is discovered that owing to the use of metakaolin and a superplasticizer, the concrete compressive strength increases. Furthermore, the use of modifiers and fiber reinforcement increases the flexural strength, frost resistance, and wear resistance of concrete. X-ray phase analysis of the fiberreinforced concrete structure confirm the effectiveness of the modifier effect, in particular the positive role of metakaolin as an active pozzolana. The developed fiber-reinforced concrete for rigid pavements with rational modifiers, depending on the Portland cement content, exhibits compressive strengths from 55 to $70 \mathrm{MPa}$, flexural strengths from 8 to $9.5 \mathrm{MPa}$, frost resistances from F350 to F450, and abrasion resistances from 0.3 to $0.4 \mathrm{~g} / \mathrm{cm}^{2}$. Such properties ensure the high durability of fiber-reinforced concrete and allow it to be used on road pavements that support heavy loads and traffic.
\end{abstract}

Keywords: Rigid pavement; fiber-reinforced concrete; metakaolin; polycarboxylate admixture. 


\section{INTRODUCTION}

Rigid pavements offer many service advantages over asphalt concrete pavements; the main advantages include less rutting and greater durability. However, the durability of concrete for rigid pavements is to be further improved to allow the extension of repair intervals and reduce road maintenance costs. In the climatic conditions of most European countries, the main indicators of concrete durability for rigid pavements are frost resistance and abrasion resistance.

An effective method for increasing the strength, frost resistance, crack resistance, and abrasion resistance of concrete rigid pavements is by using fiber reinforcement [1]. Fiber reinforcement reduces the thickness of the road pavement without reducing its bearing capacity [2]. Fiber reinforcement improves concrete properties by allowing the fibers to withstand tensile stresses and reduce shrinkage and swelling deformations [3].

In recent years, polypropylene fibers have been used widely on rigid concrete pavements. Polypropylene exhibits high chemical resistance to alkaline environments and is one of the most environmentally friendly materials for the production of fiber-reinforced concrete, since it afford the lowest carbon emission in the production of the final material $[4,5]$.

Owing to the same characteristics, polypropylene-fiber-reinforced concrete can afford cheaper rigid road pavements than steel fiber concrete and unreinforced concrete [2].

However, to achieve high concrete durability for rigid pavements, only effective modifiers can be used, i.e., polycarboxylate superplasticizers in particular. The molecular structure of polycarboxylates contributes to the acceleration of cement hydration, and the rapid adsorption of water molecules on cement particles enables larger surface or hydration reactions [6].

Pozzolans, including metakaolin, are effective modifiers that can increase the durability of concrete for rigid pavements [7-10]. Metakaolin affects the process of cement matrix structure formation and decreases concrete permeability, shrinkage, and frost resistance [1, 7, 11-13]. In addition, the use of metakaolin enables highstrength concretes of grade $C 50 / 60$ to be obtained as well as the control of early age strength $[9,14]$. However, metakaolin involves a high dispersion and provides a positive effect only when used in conjunction with a plasticizer to reduce the amount of water in the mixture [8].

\section{MATERIALS AND METHODS}

Research pertaining to fiber-reinforced concrete properties for rigid pavements has been conducted using experimental design techniques [15].

In this study, a four-factor experiment was performed based on an optimal design. The following composition factors were varied:

- $X_{1}$, amount of Portland cement (CEM II/A-S 42.5), from 400 to $500 \mathrm{~kg} / \mathrm{m}^{3}$;

- $X_{2}$, amount of polypropylene fiber (length $12 \mathrm{~mm}$; diameter $20 \mu \mathrm{m}$ ), from 0 to $2 \mathrm{~kg} / \mathrm{m}^{3}$;

- $\mathrm{X}_{3}$, amount of metakaolin (dispersed product obtained via heat treatment of enriched natural kaolin). Heat treatment forms amorphous aluminum silicate $\mathrm{Al}_{2} \mathrm{O}_{3} \cdot 2 \mathrm{SiO}_{2}$, from 0 to $30 \mathrm{~kg} / \mathrm{m}^{3}$;

- $\mathrm{X}_{4}$, amount of polycarboxylate-type superplasticizer Coral ExpertSuid-5, from $0.6 \%$ to $1 \%$ by weight of cement.

When calculating the experimental statistical models, the variation range of the factors was coded from -1 to +1 , as follows:

$$
x_{i}=\frac{X_{i}-\frac{X_{i \cdot \max }+X_{i . \min }}{2}}{\frac{X_{i . \max }-X_{i . \min }}{2}}
$$

The experimental plan and the compositions of the investigated concrete and fiber-reinforced concrete are listed in Table 1.

Mishutin, A, Kroviakov, S, Kryzhanovskyi, V, Chintea, L 
Table 1 Experimental plan and compositions of investigated concrete and fiber-reinforced concrete

\begin{tabular}{|c|c|c|c|c|c|c|c|c|c|c|c|}
\hline \multirow[b]{2}{*}{ № } & \multicolumn{4}{|c|}{ Factor levels } & \multicolumn{7}{|c|}{ Concrete mixtures (composition of $1 \mathrm{~m}^{3}$ of concrete mix) } \\
\hline & 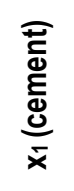 & 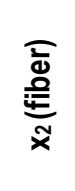 & 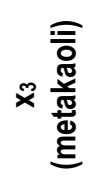 & 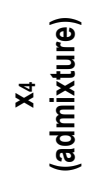 & 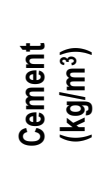 & 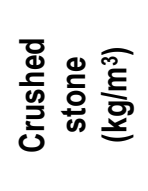 & 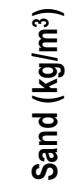 & 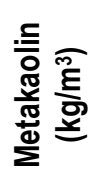 & 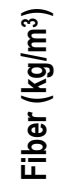 & 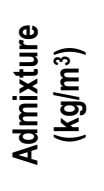 & 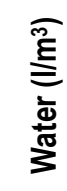 \\
\hline 1 & 0 & 0 & 0 & 0 & 450 & 1115 & 655 & 15 & 1 & 3.6 & 183 \\
\hline 2 & -1 & -1 & 1 & -1 & 400 & 1130 & 668 & 30 & 0 & 2.4 & 191 \\
\hline 3 & -1 & 1 & -1 & 1 & 400 & 1135 & 692 & 0 & 2 & 4.0 & 193 \\
\hline 4 & 1 & -1 & -1 & 1 & 500 & 1105 & 635 & 0 & 0 & 5.0 & 168 \\
\hline 5 & 1 & 1 & 1 & 1 & 500 & 1100 & 603 & 30 & 2 & 5.0 & 181 \\
\hline 6 & 1 & 1 & -1 & -1 & 500 & 1105 & 621 & 0 & 2 & 3.0 & 192 \\
\hline 7 & 0 & 1 & 1 & -1 & 450 & 1115 & 617 & 30 & 2 & 2.7 & 206 \\
\hline 8 & 0 & -1 & -1 & -1 & 450 & 1115 & 684 & 0 & 0 & 2.7 & 161 \\
\hline 9 & 0 & -1 & 1 & 1 & 450 & 1115 & 651 & 30 & 0 & 4.5 & 164 \\
\hline 10 & 1 & 0 & 1 & -1 & 500 & 1105 & 574 & 30 & 1 & 3.0 & 203 \\
\hline 11 & -1 & 0 & -1 & -1 & 400 & 1130 & 691 & 0 & 1 & 2.4 & 192 \\
\hline 12 & -1 & 0 & 1 & 1 & 400 & 1130 & 672 & 30 & 1 & 4.0 & 182 \\
\hline 13 & 1 & -1 & 0 & -1 & 500 & 1105 & 601 & 15 & 0 & 3.0 & 199 \\
\hline 14 & -1 & 1 & 0 & -1 & 400 & 1130 & 676 & 15 & 2 & 2.4 & 199 \\
\hline 15 & -1 & -1 & 0 & 1 & 400 & 1135 & 702 & 15 & 0 & 4.0 & 158 \\
\hline 16 & 1 & -1 & 1 & 0 & 500 & 1105 & 590 & 30 & 0 & 4.0 & 183 \\
\hline 17 & -1 & 1 & 1 & 0 & 400 & 1130 & 662 & 30 & 2 & 3.2 & 189 \\
\hline 18 & -1 & -1 & -1 & 0 & 400 & 1135 & 710 & 0 & 0 & 3.2 & 163 \\
\hline
\end{tabular}

Crushed stone of fraction 5/10 and quartz sand with a size modulus of 2.7 were used as aggregates for the fiber concretes.

The slump of all the concrete mixtures investigated was equal $(5-9 \mathrm{~cm})$. Such workability facilitates the placement of concrete mixtures for rigid pavements. Equal workability was achieved by changing the amount of water, i.e., the water-cement ratio (W/C) depended on the concrete mixture. When the W/C ratio was changed, the amount of sand in the concrete mixture was adjusted.

According to DSTU B V.2.7-224: 2009 "Concrete. Strength Control Rules," all the experimental points passed the strength tests. In addition, frost and abrasion resistance were determined for all concretes as the main indicators that affect the durability of road pavements. The frost resistance of concrete was determined using the accelerated method in salt water frozen to $-50{ }^{\circ} \mathrm{C}$, based on DSTU B V.2.7-49-96 "Concrete. Accelerated Methods for Determining Frost Resistance with Repeated Freezing and Thawing" (third method). The abrasion resistance of concrete and fiber-reinforced concrete was determined using cube samples with an edge of 7.07 cm, in accordance with DSTU B.2.7-212: 2009 "Concrete: Methods for Determining Abrasion Resistance"

\section{RESULTS AND DISCUSSION}

Because all mixtures exhibited the same workability, the W/C of the mixture depended on the composition. It was discovered that the W/C ratio of the mixtures investigated, depending on the composition, varied in the range from 0.33 to 0.49 . As the cement content increases, the W/C ratio of the mixtures is expected to decrease. The incorporation of polypropylene fiber renders it necessary to increase the W/C ratio to maintain the necessary mixture workability. Owing to the additional water demand of metakaolin upon its introduction, the mixture W/C

Mishutin, A, Kroviakov, S, Kryzhanovskyi, V, Chintea, L 
ratio increased by $5.8 \%$. Increasing the amount of polycarboxylate admixture from $0.6 \%$ to $0.8 \%$ and $0.9 \%$ of the cement content reduced the mixture W/C ratio by $10 \%$ and $13 \%$, respectively.

The values of compressive strength, flexural strength, frost, and abrasion resistance of the investigated concretes and fiber-reinforced concretes at 18 control points are listed in Table 2.

Table 2 Compressive strength, flexural strength, frost resistance, and abrasion resistance of investigated concretes and fiber-reinforced concretes

\begin{tabular}{ccccc}
\hline № & $\begin{array}{c}\text { Compressive strength } \\
\mathbf{f}_{\mathrm{cm}}(\mathbf{M P a})\end{array}$ & $\begin{array}{c}\text { Flexural strength } \mathrm{f}_{\text {c.tf }} \\
(\mathbf{M P a})\end{array}$ & $\begin{array}{c}\text { Frost resistance } \mathbf{F} \\
\text { (cycles) }\end{array}$ & $\begin{array}{c}\text { Abrasion resistance } \\
\mathbf{G}\left(\mathbf{g} / \mathbf{c m}^{2}\right)\end{array}$ \\
\hline 1 & 59.4 & 8.32 & 400 & 0.35 \\
2 & 49.3 & 6.97 & 250 & 0.53 \\
3 & 45.2 & 7.21 & 300 & 0.41 \\
4 & 66.1 & 8.72 & 350 & 0.47 \\
5 & 65.0 & 9.22 & 450 & 0.29 \\
6 & 54.4 & 8.73 & 400 & 0.36 \\
7 & 51.1 & 8.49 & 300 & 0.36 \\
8 & 54.8 & 7.91 & 300 & 0.50 \\
9 & 65.4 & 8.22 & 350 & 0.45 \\
10 & 55.5 & 8.47 & 400 & 0.39 \\
11 & 41.8 & 7.35 & 250 & 0.45 \\
12 & 49.1 & 7.46 & 300 & 0.41 \\
13 & 56.6 & 8.07 & 350 & 0.46 \\
14 & 46.3 & 7.78 & 300 & 0.44 \\
15 & 60.9 & 7.61 & 300 & 0.49 \\
16 & 65.2 & 8.24 & 400 & 0.43 \\
17 & 51.1 & 7.62 & 300 & 0.42 \\
18 & 49.4 & 7.07 & 250 & 0.48 \\
\hline
\end{tabular}

Using the data listed in Table 2, an experimental-statistical model was obtained (2), which describes the effect of variable composition factors on the compressive strength of fiber-reinforced concrete for rigid pavements.

$$
\begin{gathered}
f_{c m}(M p a)=59.4+5.9 x_{1}-2.4 x_{1}^{2}+1.1 x_{1} x_{2} \pm 0 x_{1} x_{3}+1.1 x_{1} x_{4}-2.0 x_{2}+2.4 x_{2}^{2} \pm 0 x_{2} x_{3} \\
-1.0 x_{2} x_{4}+1.6 x_{3}-3.1 x_{3}^{2} \pm 0 x_{3} x_{4}+1.5 x_{4}-1.9 x_{4}^{2}
\end{gathered}
$$

The analysis shows that the fiber amount did not significant affect the compressive strength. As the cement content increases, the strength of the fiber-reinforced concrete for rigid pavements is expected to increase. Using the experimental-statistical model (2), a diagram was drawn (as shown in Fig. 1), which reflects the effect of the metakaolin content and superplasticizer on the compressive strength of the fiber-reinforced concrete (at medium dosages of cement and fiber). An analysis of the diagram shows that the rational metakaolin content in terms of providing increased compressive strength was from 15 to $20 \mathrm{~kg} / \mathrm{m}^{3}$, and the volume of polycarboxylate superplasticizer was within $0.8 \%$ to $0.9 \%$ of the cement content. 


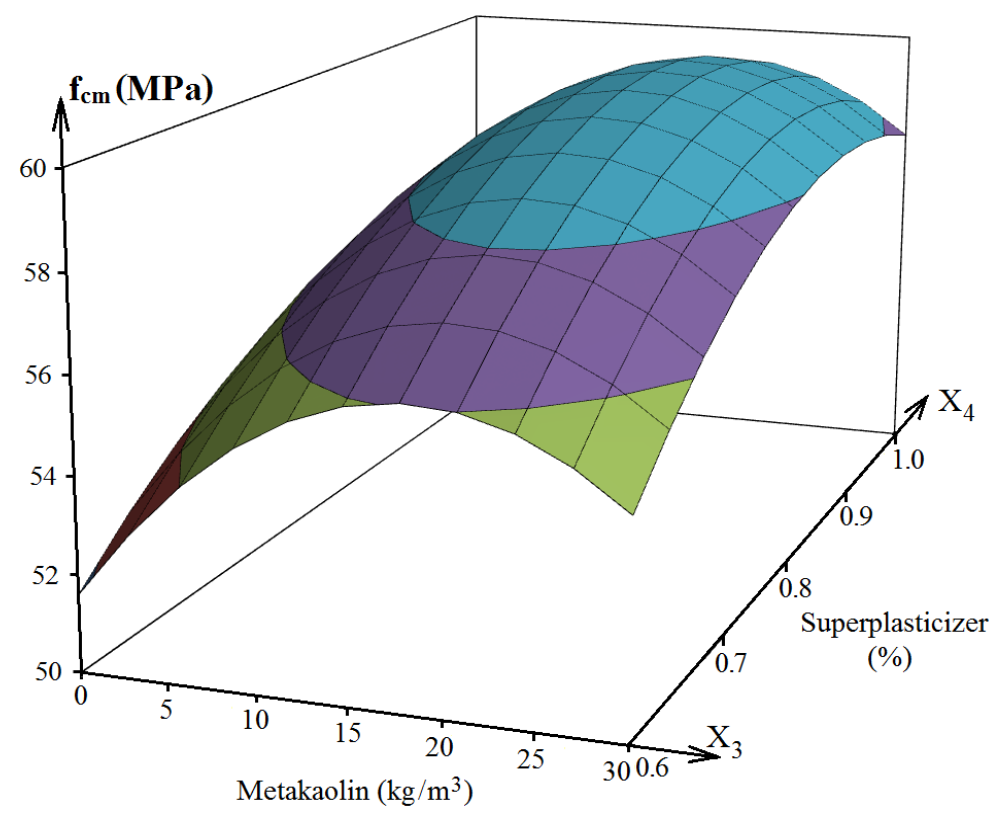

Figure 1 Effects of metakaolin content and superplasticizer on compressive strength of fiber-reinforced concrete $\left(x_{1}=x_{2}=0\right.$; cement content $=450 \mathrm{~kg} / \mathrm{m}^{3}$; polypropylene fiber content $\left.=1 \mathrm{~kg} / \mathrm{m}^{3}\right)$

Flexural strength is an important characteristic of road pavement. The effects of the factors on this indicator were analyzed using a similar experimental-statistical model (2). The data in Table 2 were used to calculate the model. It was determined that the dispersed reinforcement increased the concrete flexural strength by 0.5 to 0.9 $\mathrm{MPa}$. Owing to dispersed reinforcement and complex modification with metakaolin and a polycarboxylate superplasticizer, the concrete flexural strength for rigid pavements increased by 1.2 to $1.4 \mathrm{MPa}$ and reached 8.59.3 MPa. In general, the use of rational amounts of polypropylene fiber and metakaolin as pozzolan additives can significantly increase the concrete strength of road pavements.

Road pavements are simultaneously affected by operational and climatic factors, such as temperature changes, cyclic freezing and thawing, moistening and drying, loads, and dynamic effects from transport. The number of freezing and thawing cycles of pavements can be significantly greater than the number of air temperature transitions through $0{ }^{\circ} \mathrm{C}$. Under such conditions, the main quality indicators that provide concrete durability for rigid pavements are frost resistance and abrasion resistance. Furthermore, frost resistance characterizes the concrete stability not only under freezing and thawing conditions, but also under cyclic temperature changes in a positive range.

The diagrams in Fig. 2 represent the effects of the contents of metakaolin and a superplasticizer (Fig. 2.a), fiber, and a superplasticizer (Fig. 2.b) on the concrete frost resistance, drawn using a similar experimentalstatistical model (2). 

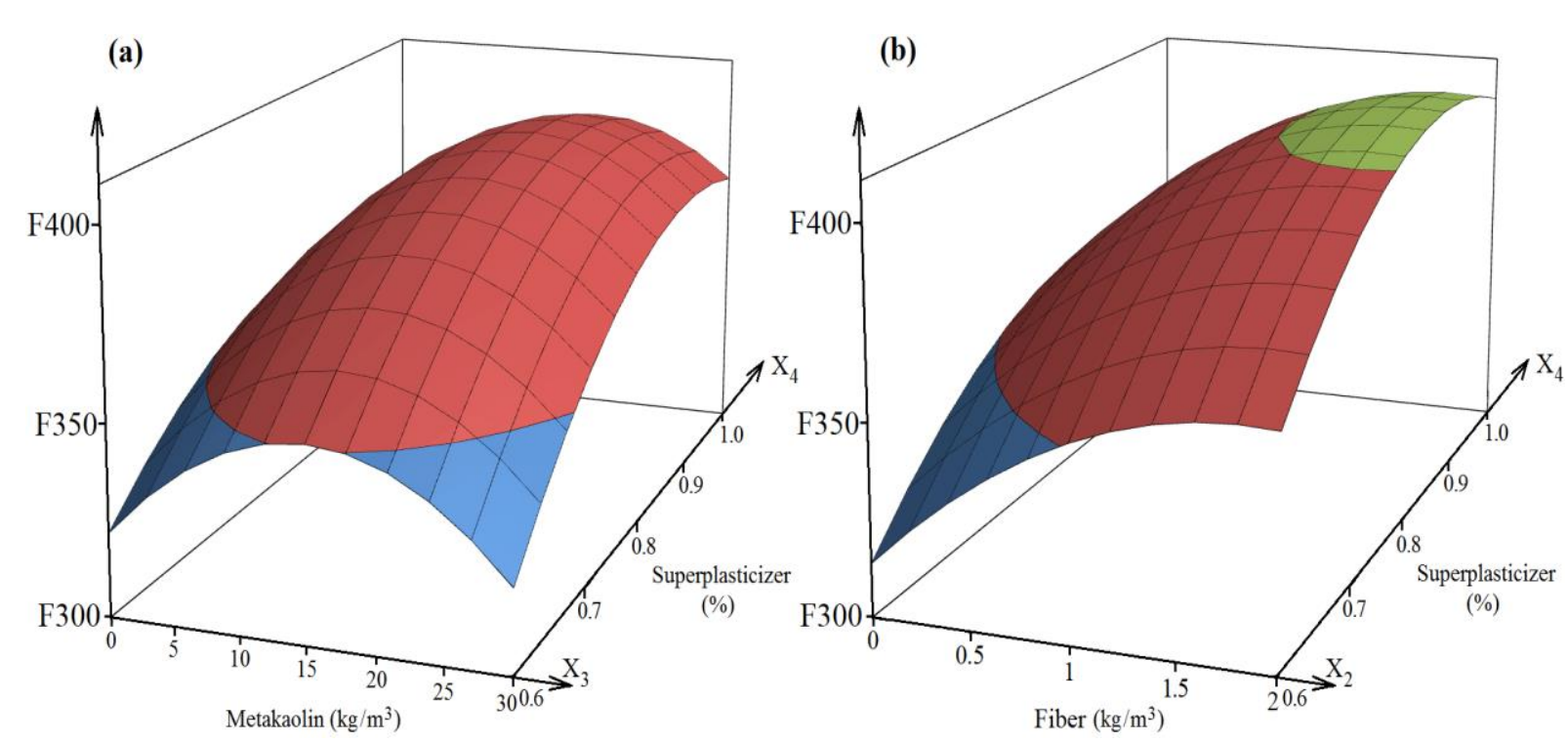

Figure 2 Effects of metakaolin and superplasticizer contents (a) and fiber and superplasticizer contents (b) on frost resistance of fiber-reinforced concrete. Dosage of factors (not presented) was at middle level of range

An analysis of the diagrams shown in Fig. 2 shows that, owing to the use of rational amounts of a superplasticizer $(0.8-0.9 \%)$ and metakaolin $\left(15-20 \mathrm{~kg} / \mathrm{m}^{3}\right)$ as well as dispersed fiber reinforcement in a volume of $1-1.5 \mathrm{~kg} / \mathrm{m}^{3}$, the concrete frost resistance increased by approximately 100 cycles in comparison with concretes modified with a minimum amount of superplasticizer.

The experimental-statistical model, which represents the effect of variable composition factors on the abrasion resistance of fiber-reinforced concrete rigid pavements, is expressed as follows:

$G=0.350-0.036 x_{1} \pm 0.020 x_{1}^{2}-0.016 x_{1} x_{2}-0.008 x_{1} x_{3} \pm 0 x_{1} x_{4}-0.056 x_{2}+0.030 x_{2}^{2} \pm$ $0 x_{2} x_{3} \pm 0 x_{2} x_{4}-0.006 x_{3}+0.012 x_{3}^{2} \pm 0 x_{3} x_{4}-0.018 x_{4}+0.022 x_{4}^{2}\left[\mathrm{~g} / \mathrm{cm}^{2}\right]$

Model (3) was calculated using the data presented in Table 2. The model analysis showed that the most significant factors that affected the abrasion of the investigated concretes was the fiber amount and Portland cement content, whereas the least significant factor was the metakaolin content. Furthermore, concretes with 15$20 \mathrm{~kg} / \mathrm{m}^{3}$ of the active mineral additive were characterized by a 6-8 \% lower abrasion compared with those without metakaolin. To perform a more detailed analysis regarding the effects of the superplasticizer and polypropylene fiber amounts on the abrasion of the investigated fiber-reinforced concrete, a diagram was drawn, as shown in Fig. 3. 


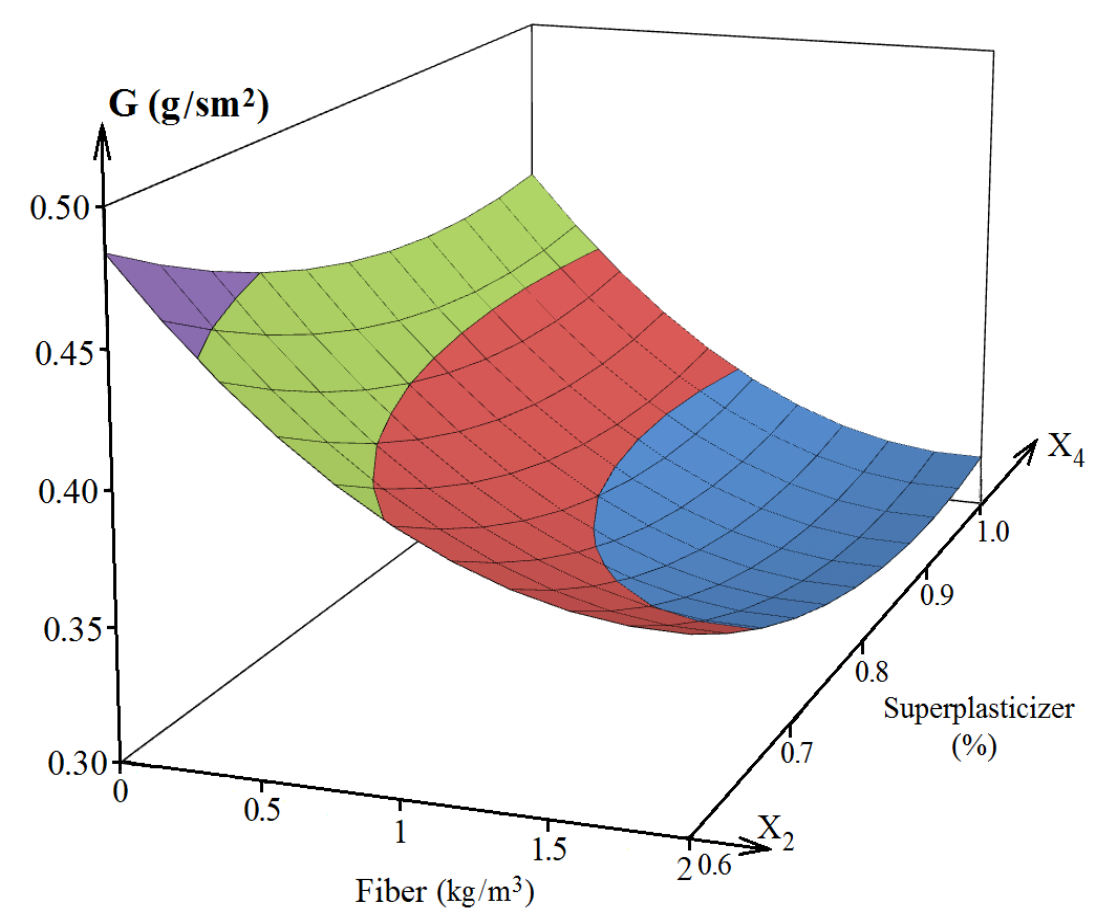

Figure 3 Effects of fiber and superplasticizer amounts on abrasion of fiber concretes. Dosage of factors (not presented was at middle level of range $\left(x_{1}=x_{3}=0\right.$; cement content $=450 \mathrm{~kg} / \mathrm{m}^{3}$; metakaolin content $=$ $\left.15 \mathrm{~kg} / \mathrm{m}^{3}\right)$

An analysis of the diagram shows that dispersed reinforcement is an effective method for improving the abrasion resistance of rigid pavements. By incorporating $1.5-2 \mathrm{~kg} / \mathrm{m}^{3}$ of polypropylene fiber, the concrete abrasion decreased by $0.11-0.16 \mathrm{~g} / \mathrm{cm}^{2}$, which, depending on the composition, corresponded to a decrease by $22 \%$ to $35 \%$. In addition, the superplasticizer contributed positively to the concrete abrasion resistance, owing to an increase in the polycarboxylate superplasticizer amount from $0.6 \%$ to $0.9 \%$. Meanwhile, the W/C ratio of the mixture decreased, and the concrete strength increased, which reduced its abrasion level. The complex application of fiber and the addition of a rational amount of superplasticizers can reduce the concrete abrasion by $40 \%-45 \%$.

Therefore, applying dispersed reinforcement and a rational amount of modifiers (polycarboxylate superplasticizer and metakaolin) allows concrete for rigid pavements with high strength and durability to be achieved via an increase in the frost resistance and a decrease in abrasion, it is rational to use $1.2-1.6 \mathrm{~kg} / \mathrm{m}^{3}$ of fiber, $15-20 \mathrm{~kg} / \mathrm{m}^{3}$ of metakaolin, and a superplasticizer with $0.9 \%$ cement content.

To identify the modifier effect on the structures of the investigated fiber-reinforced concrete, an X-ray phase analysis of the cement and matrix was performed. Samples from control points № 1 (average amount of metakaolin, superplasticizer, and fiber), № 6 (absence of metakaolin, minimum amount of superplasticizer, and maximum amount of fiber), № 8 (absence of metakaolin and fiber, minimum amount of superplasticizer), and № 9 (maximum amount of metakaolin and superplasticizer, no fiber) were analyzed. The compositions of the samples investigated are listed in Table 1.

Based on the X-ray phase analysis (Fig. 4), the stone diffraction patterns of the cements and matrix samples from points № 1, № 6, № 8, and № 9 reflect the characteristic lines of $\beta$-quartz, feldspar such as orthoclase and anorthite, as well as hydromica, which are rock-forming minerals of fine aggregates, i.e., sand. The low reflex intensity of non-hydrated Portland cement clinker minerals - alite and belite phases $(\mathrm{d} / \mathrm{n}=0.302$, $0.274,0.276$, and $0.218 \mathrm{~nm}$ ) indicates the completeness of the hydration processes. The main hydration products of the cement-sand matrix without metakaolin (sample № 8) were ettringite $(\mathrm{d} / \mathrm{n}=0.973,0.561$, and $0.256 \mathrm{~nm}$ ) and calcium hydroxide $\mathrm{Ca}(\mathrm{OH})_{2}(\mathrm{~d} / \mathrm{n}=0.493,0.263,0.193$, and $0.179 \mathrm{~nm})$. The fiber addition to the composition of the cementsand matrix (sample № 6) did not change the mechanism of the hydration processes, and the main 
products of hydration were represented by ettringite $(\mathrm{d} / \mathrm{n}=0.973,0.561$, and $0.256 \mathrm{~nm})$ and $\mathrm{Ca}(\mathrm{OH})_{2}(\mathrm{~d} / \mathrm{n}=$ $0.493,0.263,0.193$, and $0.179 \mathrm{~nm}$ ).

Using the average amounts of metakaolin, superplasticizer, and fiber (№ 1) in the cement-sand matrix composition the number of characteristic lines indicating the intensity of $\mathrm{Ca}(\mathrm{OH})_{2}$ decreased slightly owing to pozzolanic reactions between the active $\mathrm{SiO}_{2}$ and $\mathrm{Al}_{2} \mathrm{O}_{3}$ of metakaolin and portlandite, resulting in the formation of hydrosilicates and calcium hydroaluminates. The effects of the maximum amounts of metakaolin and superplasticizer (№ 9) on the phase composition of the cements and matrix were due to the intense and depth of the pozzolanic reaction, as evidenced by a 1.5 -fold decrease in $\mathrm{Ca}(\mathrm{OH})_{2}$ reflections with the formation of calcium hydrosilicates and hexagonal calcium hydroaluminatives of the $\mathrm{C}_{4} \mathrm{AH} \mathrm{H}_{13}$ type $(\mathrm{d} / \mathrm{n}=0.79$ and 0.247$)$. Hence, the $\mathrm{X}$ ray phase analysis of the investigated fiber-reinforced concrete structure confirmed the effectiveness of the modifiers used, in particular, the positive effect of metakaolin as an active pozzolana.
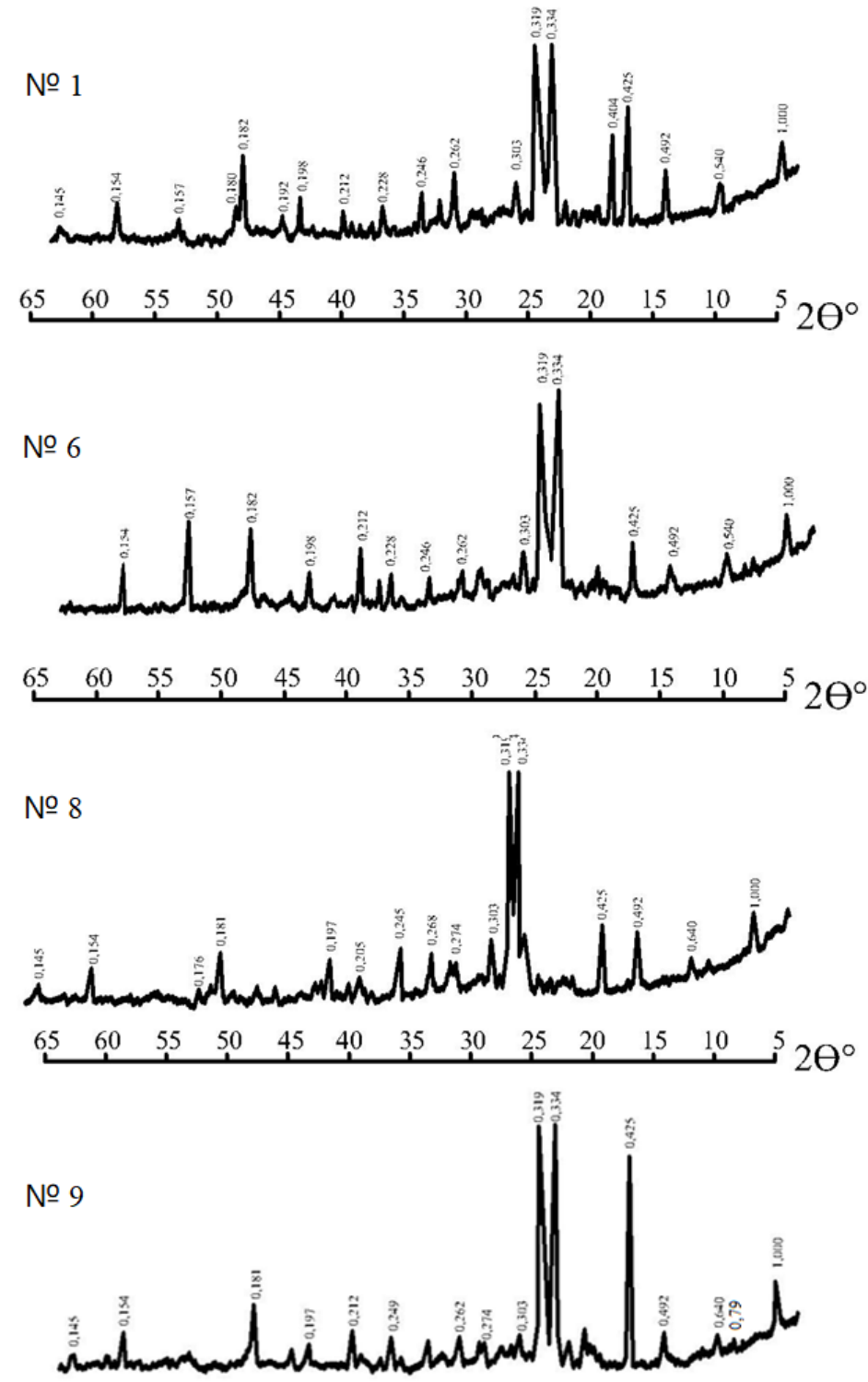

$\begin{array}{rrrrrrrrrrrrr}65 & 60 & 55 & 50 & 45 & 40 & 35 & 30 & 25 & 20 & 15 & 10 & 5\end{array} 2 \theta^{\circ}$

Figure $4 \mathrm{X}$-ray diffraction patterns of cement-sand matrix samples of investigated fiber-reinforced concrete 


\section{CONCLUSIONS}

A four-factor experiment and analysis of a set of experimental-statistical models enabled rational amounts of polypropylene fiber (1.2-1.6 kg/m 3 ), a polycarboxylate-type superplasticizer $(0.9 \%$ of the cement content), and metakaolin $15-20 \mathrm{~kg} / \mathrm{m}^{3}$ to be incorporated in the composition of fiber-reinforced concrete pavement. Owing to the use of optimal amounts of a polycarboxylate superplasticizer and metakaolin as a pozzolana-type additive, as well as dispersed reinforcement comprising polypropylene fiber, fiber-reinforced concrete for rigid pavements with increased strength (maximum compressive strength of 55-71 MPa; maximum flexural strength of 8.59.3 MPa), frost resistance (F400-F450), and abrasion resistance $\left(<0.35 \mathrm{~g} / \mathrm{cm}^{2}\right)$ that afforded high durability under typical operating conditions was achieved. The positive effect of metakaolin as an active pozzolana was confirmed via the X-ray phase analysis of the fiber-reinforced concrete structure.

\section{References}

[1] Gupta, S.; Rao, V. K.; Sengupta, J. 2008: Evaluation of polyester fiber reinforced concrete for use in cement concrete pavement works, Road materials and pavement design, 9 (3), pp. 441-461. https://doi.org/10.1080/14680629.2008.9690127

[2] Hussain, I.; Ali, B.; Akhtar, T.; Jameel, M. S.; Raza, S. S. 2020: Comparison of mechanical properties of concrete and design thickness of pavement with different types of fiber-reinforcements (steel, glass, and polypropylene), Case Studies in Construction Materials, 13, e00429. https://doi.org/10.1016/i.cscm.2020.e00429

[3] Choi, S. Y.; Park, J. S.; Jung, W. T. 2011: A study on the shrinkage control of fiber reinforced concrete pavement, Procedia engineering, 14, pp. 2815-2822. https://doi.org/10.1016/i.proeng.2011.07.354

[4] Ali, B., et al. 2020: Effect of varying steel fiber content on strength and permeability characteristics of high strength concrete with micro silica, Materials, 13 (24), 5739. https://doi.org/10.3390/ma13245739

[5] Devi, K. S.; Lakshmi, V. V.; Alakanandana, A. 2017: Impacts of cement industry on environment-an overview, Asia Pacific Journal of Research, 1 (LVII), pp. 156-161.

[6] Liu, J.; Yu, C.; Shu, X.; Ran, Q.; Yang, Y. 2019: Recent advance of chemical admixtures in concrete, Cement and Concrete Research, 124, 105834. https://doi.org/10.1016/j.cemconres.2019.105834

[7] Busari, A.; Akinmusuru, J.; Dahunsi, B. 2019: Mechanical properties of dehydroxylated kaolinitic clay in selfcompacting concrete for pavement construction, Silicon, 11 (5), pp. 2429-2437. https://doi.org/10.1007/s12633-017-9654-6

[8] Salimi, J.; Ramezanianpour, A. M.; Moradi, M. J. 2020: Studying the effect of low reactivity metakaolin on free and restrained shrinkage of high performance concrete, Journal of Building Engineering, 28, 101053. https://doi.org/10.1016/i.jobe.2019.101053

[9] Patil, S. N.; Gupta, A. K.; Deshpande, S. S. 2013: Metakaolin-Pozzolanic material for cement in high strength concrete, In Proceedings of the 2nd International Conference on Emerging Trends in Engineering (SICETE'13), pp. 46-49.

[10] Kroviakov, S.; Zavoloka, M.; Dudnik, L.; Kryzhanovskyi, V. 2019: Comparison of strength and durability of concretes made with sulfate-resistant portland cement and portland cement with pozzolana additive, Electronic Journal of the faculty of civil engineering Osijek-e-GFOS, 10 (19), pp. 81-86. https://doi.org/10.13167/2019.19.8

[11] Ženíšek, M.; Vlach, T.; Laiblová, L. 2017: Dosage of metakaolin in high performance concrete, Key Engineering Materials, 722, pp. 311-315. https://doi.org/10.4028/www.scientific.net/KEM.722.311

[12] Dinakar, P.; Sahoo, P. K.; Sriram, G. 2013: Effect of metakaolin content on the properties of high strength concrete, International Journal of Concrete Structures and Materials, 7 (3), pp. 215-223. https://doi.org/10.1007/s40069-013-0045-0

[13] Narmatha, M.; Felixkala, T. 2016: Meta kaolin-the best material for replacement of cement in concrete, IOSR Journal of Mechanical and Civil Engineering, 13 (4), pp. 66-71. https://doi.org/10.9790/16841304016671

[14] Srivastava, V.; Kumar, R.; Agarwal, V. C.; Aai-du, S. F. 2012: Metakaolin inclusion: Effect on mechanical properties of concrete, Journal of Academia and Industrial Research, 1 (5), pp. 251-253.

Mishutin, A, Kroviakov, S, Kryzhanovskyi, V, Chintea, L 
Fiber-reinforced concrete for rigid road pavements modified with polycarboxylate admixture and metakaolin

[15] Giesbrecht, F. G.; Gumpertz, M. L. 2004: Planning, construction, and statistical analysis of comparative experiments, John Wiley \& Sons, Hoboken, New Jersey, USA. https://doi.org/10.1002/0471476471

Please cite this article as: Mishutin, A., Kroviakov, S., Kryzhanovskyi, V., Chintea, L.: Fiber-reinforced concrete for rigid road pavements modified with polycarboxylate admixture and metakaolin, Electronic Journal of the Faculty of Civil Engineering Osijek-e-GFOS, 2021, 23, pp. 1-10, https://doi.org/10.13167/2021.23.1

Mishutin, A, Kroviakov, S, Kryzhanovskyi, V, Chintea, L 